\title{
O profissional cultivado para os campos de Relações Públicas e de Comunicação Organizacional
}

\author{
The professional who is cultivated for the fields \\ of Public Relations and Organizational Communication
}

\section{El profesional cultivado para los campos de Relaciones Públicas y de Comunicación Organizacional}

Cláudia Peixoto de Moura

- Pós-Doutorado em Comunicação pela Universidade de Coimbra (Portugal)

- Doutorado em Ciências da Comunicação pela Universidade de São Paulo (ECA-USP).

- Mestrado em Sociologia pela Pontifícia Universidade Católica do Rio Grande do Sul (PUC-RS)

- Especialização em Publicidade e Propaganda (1981), Estilo Jornalístico (1982) e Administração em Relações Públicas (1986), pela PUC-RS

- Graduação em Publicidade e Propaganda (1979), Jornalismo (1980) e Relações Públicas (1984), pela PUC-RS.

- Professora titular e coordenadora do Departamento de Ciências da Comunicação da Faculdade de Comunicação Social da PUC-RS

- Diretora científica da Associação Brasileira de Pesquisadores de Comunicação Organizacional e de Relações Públicas (Abrapcorp)

- Autora de 0 curso de comunicação social no Brasil: do currículo mínimo às novas diretrizes curriculares (2002) e organizadora de História das relações públicas: fragmentos da memória de uma área (e.book, 2008)

-cpmoura@pucrs.br 
O binômio Relações Públicas e Comunicação Organizacional permite abordagens envolvendo semelhanças, diferenças e complementaridades entre as duas áreas, que podem ser consideradas dois campos, muito mais pelas suas configurações do que propriamente pelos saberes. Ambas sofrem tensões, concorrem entre si pelos espaços e vivem suas lutas internas e externas, no sentido dado a "campo" pelo sociólogo Pierre Bourdieu. Pressupõem um capital cultural para a atuação profissional na realidade. O texto tem como objetivo abordar as questões do campo científico e do capital cultural como uma contribuição ao debate conceitual das áreas.

PALAVRAS-CHAVE: RELAÇÕES PÚBlicAS • COMUNICAÇÃO ORGANIZACIONAL • CAMPO CIENTífICO • CAPITAL CULTURAL

\section{Abstract}

The binomial Public Relations and Organizational Communication enables approaches that involve dimilarities, differences and complements between both areas, which can be considered as two fields, much more as a result of their configurations than of what their relevant knowledge represents. Both of them undergo tension, dispute for opportunities, and experience their own internal and external struggles, according to the sociologist Pierre Bourdieu. They also presume cultural capital for the professional performance in reality. The text proposes to approach matters involving the scientific field and the cultural capital as a contribuition to conceptual debates in both areas.

KEYWORDS: PUBLIC RELATIONS • ORGANIZATIONAL COMMUNICATION • SCIENTIFIC FIELD • CULTURAL CAPITAL

\section{Resumen}

El binomio Relaciones Públicas y Comunicación Organizacional permite abordajes que comprenden semejanzas, diferencias y complementariedades entre las dos áreas, que pueden considerarse dos campos diferentes, mucho más por sus configuraciones que propiamente por los saberes. Ambas sufren tensiones, compiten entre si por los espacios y viven sus luchas internas y externas, en el sentido adoptado por el sociólogo Pierre Bourdieu. Presuponen un capital cultural para la actuación profesional en la realidad. El texto tiene como objetivo abordar las cuestiones del campo científico y del capital cultural como una contribución al debate conceptual de las áreas.

PALABRAS CLAVE: RELACIONES PÚBLICAS • COMUNICACIÓN ORGANIZACIONAL • CAMPO CIENTífICO • CAPITAL CULTURAL 
A questão aqui discutida envolve campos científicos e hábitos institucionais. "O campo científico é [...] um campo de lutas como outro qualquer" (BOURDIEU, 1994, p. 24), cuja participação na luta está relacionada ao capital científico em um espaço social estruturado.

\section{Campos de relações}

Há uma relação entre as instituições e os hábitos como uma forma de incorporação do social, realizada pela aprendizagem, fundamentada em ações que garantem a sua presença na sociedade. Isto porque "o corpo está dentro do mundo social, mas o mundo social está dentro do corpo" (BOURDIEU, 1994, p. 41). As relações podem ser "entendidas como interações, ou seja, como relações intersubjetivas realmente efetuadas" (BOURDIEU, 1994, p. 45 - grifo do autor). A estrutura das relações constitui o espaço do campo, ocorrendo no espaço institucional a produção característica dos que ocupam o referido espaço, sendo que as relações de concorrência/ competição e de conflito/luta contribuem para o afrontamento dentro dos campos de Relações Públicas e de Comunicação Organizacional.

O jogo social é constituído de ações e reações manifestadas nos "campos de luta para transformar ou conservar esses campos de forças" (BOURDIEU, 1994, p. 51), no sentido de melhorar as posições dos indivíduos que aderiram ao jogo. A entrada no jogo está determinada pela relação entre o hábito e o campo, havendo um proveito além do

salário, preço, recompensa, troféu, título, função - e que consiste no fato de sair-se do anonimato, e de afirmar-se como agente, envolvido no jogo, ocupado, habitante do mundo habitado pelo mundo, orientado para certos fins e dotado objetivamente, e portanto subjetivamente, de uma missão social (BOURDIEU, 1994, p. 54),

que pode ser sancionada pelas vocações e pelo magistério, entre outros suportes da existência social. No campo "há dominantes e dominados, há relações constantes, permanentes, de desigualdade" e "cada um, no interior desse universo, empenha em sua concorrência com os outros a força (relativa) que detém e que define sua posição no campo e, em consequência, suas estratégias" (BOURDIEU, 1997, p. 57), a exemplo de Relações Públicas e de Comunicação Organizacional que agem sobre outros campos.

Então, os hábitos praticados por meio de atividades profissionais estão relacionados ao campo de lutas identificado em instâncias: a área de Comunicação Social, da qual Relações Públicas e Comunicação Organizacional fazem parte; as instituições de ensino superior que formam profissionais para uma atuação nas duas áreas; as organizações que contratam os respectivos profissionais egressos dos cursos superiores; a sociedade que recebe a produção originada 
do exercício profissional em ambas as áreas, a qual envolve práticas investigativas. A delimitação do conteúdo e o modo a ser inculcado, assim como o tempo de formação, definem o habitus, que é "o grau de realização cultural (grau de competência legítima) pelo qual um grupo ou uma classe reconhece o homem realizado" (BOURDIEU; PASSERON, 2008, p. 56). A competência está associada à cultura reconhecida em um "homem cultivado", pela inculcação implícita e explícita (formal e formalizada em processos educativos). As rotinas se estabelecem por meio de práticas pedagógicas, que podem envolver atividades de pesquisa, participando mais dos campos científico e intelectual.

\section{Capital cultural para cultivo do profissional}

O diploma, o status profissional e a capacidade reconhecida pelo título acadêmico estão relacionados a uma certificação e uma legitimação das hierarquias sociais, além de uma qualificação técnica e rentabilidade social ao "homem cultivado", que possui vantagens acadêmicas e sociais devido a sua passagem pelo ensino superior. Entretanto, há um campo de conflitos quando existe uma discussão para estabelecer as convergências e os limites conceituais entre Relações Públicas e Comunicação Organizacional.

Três questões nortearam os debates no I Fórum sobre as Bases Conceituais de Comunicação Organizacional e de Relações Públicas, da Abrapcorp ${ }^{1}$ : a) Relações Públicas e Comunicação Organizacional; b) Relações Públicas ou Comunicação Organizacional; c) Relações Públicas versus Comunicação Organizacional. Responder a essas questões significa assumir posições e riscos dentro de campos de lutas. Com o apoio dos escritos de Bourdieu faço as considerações que seguem.

A primeira questão, "Relações Públicas e Comunicação Organizacional”, se vincula ao capital cultural incorporado, pois um profissional completo necessita dos saberes das duas áreas para desenvolver suas práticas de forma abrangente e reflexiva. O capital cultural incorporado exige uma aquisição realizada pessoalmente pelo sujeito, que investe seu tempo para "cultivar-se". "O capital cultural é um ter que se tornou ser, uma propriedade que se fez corpo e tornou-se parte integrante da 'pessoa', um habitus" (BOURDIEU, 1998, p. 74-75 - grifo do autor), a partir de sua formação e da apropriação de conhecimento, de saberes.

Já a questão "Relações Públicas ou Comunicação Organizacional” pode remeter a um capital objetivado, na medida em que a produção resultante dos saberes cultivados em ambas as áreas é reconhecida como uma prática direcionada aos interesses institucionais e acadêmicos. O capital cultural objetivado diz respeito aos bens culturais, somente existindo se for apropriado e utilizado no campo da produção cultural e das classes sociais que se beneficiam com

10 I Fórum teve lugar no II Congresso Brasileiro Científico de Comunicação Organizacional e de Relações Públicas, realizado em Belo Horizonte (MG), em 2008. 
o domínio desse capital. Isso pode ser entendido como uma produção baseada nos princípios de Relações Públicas ou de Comunicação Organizacional para o benefício de instituições, no sentido de atuar na sociedade por meio de projetos de comunicação e de investigação, direcionados a objetivos distintos, conforme os interesses públicos e privados.

Por fim, a questão "Relações Públicas versus Comunicação Organizacional” caracteriza uma competição na qual as diferenças são potencializadas. Isto pode ser observado com referência ao capital cultural institucionalizado, uma vez que as Relações Públicas possuem uma certificação que garante uma legitimidade para o exercício profissional, o mesmo não ocorrendo com a Comunicação Organizacional, identificada como uma função desempenhada por um profissional de relações públicas ou de outra área. A certificação não é garantia dos saberes vinculados ao capital incorporado e objetivado, mas sim de um reconhecimento em um espaço social com profissões regulamentadas. O capital cultural institucionalizado é conferido pelo reconhecimento institucional atribuído ao certificado acadêmico, como uma garantia de competência cultural, que possui "um valor convencional, constante e juridicamente garantido no que diz respeito à cultura” (BOURDIEU, 1998, p. 78).

É um investimento que depende do rendimento acadêmico e de sua certificação para o rendimento econômico e posição social.

O tempo do diploma não é o da competência: a obsolescência das capacidades (equivalente ao desgaste das máquinas) é dissimulado-negado pela intemporalidade do diploma. [...] Resulta daí a possibilidade de uma defasagem entre as competências garantidas pelo diploma e as características dos cargos, cuja mudança, dependente da economia, é mais rápida (BOURDIEU, 1998, p. 132).

Há uma defasagem temporal na medida em que a aquisição do diploma acompanha toda a vida do sujeito. Como a força de trabalho está vinculada ao capital cultural, a relação entre cargo e diploma conserva as vantagens para uma reprodução das classes dominantes e confere poderes aos diplomados.

Tanto o capital social (rede de relações) como o capital cultural (incorporado, objetivado e institucionalizado) estão na agenda de debates. A rede de relações possibilita uma mobilização, uma multiplicação do capital possuído, além de trocas contínuas, que são ações estratégicas para um investimento social e para um investimento cultural, no qual o indivíduo é "cultivado" (possuidor de um "habitus"), certificado (com garantia de competências) e qualificado (com vantagens sociais). Os cursos de Comunicação pressupõem um investimento no capital cultural que está associado ao capital social, estabelecendo uma rede de ligações na qual a pesquisa acadêmica tem um papel relevante. Um "habitus cultivado", competências definidas pelos cursos, diplomas reconhecidos no espaço social, qualificações na formação são investimentos econômicos para as sociedades globalizadas. 


\section{Rede de relações}

Os debates do II Fórum da Abrapcorp ${ }^{2}$ foram pautados por outras questões, considerando-se neste texto a que tratava dos saberes para a fundamentação das áreas. A formação superior capacita os profissionais com base em conhecimentos gerais e específicos para ampliar o capital cultural incorporado, cultivado nos bancos universitários, resultando em um capital cultural objetivado por meio de uma produção de projetos qualificados, com a vantagem assegurada pelo certificado de conclusão da graduação. Independentemente do fato de o diploma ser exigido para o exercício profissional, é a existência de uma certificação que legitima a autoridade do graduado na área em uma "sociedade de títulos”. Porém, são os saberes que fundamentam ambas as áreas, implicando estratégias para a apropriação dos conhecimentos de referência.

Os conhecimentos gerais fornecem uma bagagem cultural necessária para o entendimento da realidade, para uma reflexão sobre a sociedade, por meio das práticas de comunicação. Os conhecimentos específicos, envolvendo teorias e técnicas, podem capacitar o profissional para uma atuação responsável e ética na atividade de Relações Públicas ou na função de Comunicação Organizacional. As ciências que estudam a sociedade, aplicadas ao campo da Comunicação, embasam o debate nas áreas de Relações Públicas e de Comunicação Organizacional. Refletir sobre as práticas profissionais significa uma necessidade, em uma sociedade cada vez mais caracterizada pelo conhecimento e pela informação. Assim, os saberes possibilitam traçar caminhos nos diversos espaços sociais.

O capital social e o capital cultural são aspectos fundamentais das relações existentes no espaço social.

O capital social é o conjunto de recursos atuais ou potenciais que estão ligados à posse de uma rede durável de relações mais ou menos institucionalizadas de interconhecimento e de inter-reconhecimento ou, em outros termos, à vinculação a um grupo, como conjunto de agentes que não somente são dotados de propriedades comuns (passíveis de serem percebidas pelo observador, pelos outros ou por eles mesmos), mas também são unidos por ligações permanentes e úteis (BOURDIEU, 1998, p. 67 - grifos do autor).

As relações contingentes podem ser transformadas em relações necessárias quando "a rede de ligações é o produto de estratégias de investimento social consciente ou inconscientemente orientadas para a instituição ou a reprodução de relações sociais diretamente utilizáveis, em curto ou longo prazo" (BOURDIEU, 1998, p. 68), com competência e disposição em termos de tempo e esforços, muitas vezes econômicos.

20 II Fórum sobre as Bases Conceituaiis de Comunicação Organizacional e de Relações Públicas ocorreu durante o III Congresso Brasileiro Científico de Comunicação Organizacional e de Relações Públicas, realizado em São Paulo (SP), em 2009. 
Portanto, a relação entre o capital social - rede de relações - e o capital cultural - incorporado, objetivado e institucionalizado - permitirá um aprofundamento dos processos de relacionamentos, entre públicos e organizações, pelas ações de comunicação. Segundo Simões (1995), a definição operacional para a atividade de Relações Públicas identifica sua prática em quatro etapas: a) diagnóstico - da situação presente, em termos de filosofia, objetivos e ações de comunicação; b) prognóstico - visão de futuro, com base no diagnóstico; c) elaboração de pareceres - para os procedimentos organizacionais, assessorando e implementando ações para resolver problemas; d) avaliação de ações - controle dos resultados das ações de comunicação para retroalimentar o sistema com informações. O termo "comunicação" engloba ações estratégicas, dirigidas e integradas, que são trabalhadas considerando-se também o entendimento de Comunicação Organizacional, além dos interesses voltados à Comunicação Institucional, Corporativa, Pública ou Cívica. São as trajetórias, os percursos possíveis na rede de relações que o profissional "cultivado" poderá vislumbrar.

\section{Referências}

BOURDIEU, Pierre. Escritos de educação. Petrópolis, RJ: Vozes, 1998.

BOURDIEU, Pierre. Sobre a televisão. Rio de Janeiro: Zahar, 1997.

. Lições de aula. 2. ed. São Paulo: Ática, 1994.

BOURDIEU, Pierre; PASSERON, Jean-Claude. A reprodução: elementos para uma teoria do sistema de ensino. Petrópolis, RJ: Vozes, 2008.

SIMÕES, Roberto Porto. Relações públicas: função política. 3. ed. rev. e ampl. São Paulo: Summus, 1995. 